\title{
O EXISTENCIALISMO EM PASCAL ${ }^{1}$
}

\author{
Ivonil PARRAZ ${ }^{2}$
}

n RESUMO: O homem traz inscrito no mais profundo do seu ser "a marca do nada", "o traço vazio". Porque traz esse vazio, ele tudo faz para preenchê-lo. Cria "eus imaginários" formando-os com as qualidades que estima e que os outros também estimam; tenta impô-los aos outros buscando assim a admiração alheia. O eu imaginário permite a ele livrar-se da visão do seu eu verdadeiro. Esse eu que o coloca diante do seu vazio, produz nele o tédio e a inquietude.

n PALAVRAS-CHAVE: Nada; angústia; divertimento; admiração; estima.

"Nada é tão insuportável ao homem, quanto estar em pleno repouso, sem paixões, sem negócios, sem divertimento, sem atividades. Ele então sente seu nada, seu abandono, sua insuficiência, sua dependência, sua impotência, seu vazio. Imediatamente sairá do fundo de sua alma o tédio, o negrume, a tristeza, a aflição, o despeito, o desespero", afirma Pascal no fragmento 131 dos Pensamentos.

Esta afirmação basta, por si só, para revelar a leitura que Pascal faz do homem empírico, do homem que experimenta em seu interior o vazio e, buscando socorro nas coisas exteriores, tudo faz para preenchê-lo. Os termos essenciais para a compreensão da leitura pascaliana do homem tal como ele se apresenta são: angústia e divertimento.

\footnotetext{
1 O presente artigo é fruto de uma palestra apresentada na XXVI Jornada de Filosofia e Teoria da Ciências Humanas - a filosofia da existência e a tragédia moderna, FFC/UNESP - Marília, em $07 / 11 / 2002$.

2 Doutorando em Filosofia - FFLCH - Universidade de São Paulo - USP
} 
No século XVII o termo ennui, que pode ser traduzido por similares em português tais como: aborrecimento, angústia, tédio, entre outros, tinha uma forte conotação de angústia essencial, associada à impossibilidade de sair de tal estado, como uma espécie de patologia espiritual. O termo divertissement, por sua vez, tinha um forte caráter militar: desviar de inimigos, manobras estratégicas. Podemos traduzir esse termo como: desviar de obstáculos indesejáveis, divertir-se, alienar-se.

Assim, o divertimento é a forma privilegiada que o homem encontra para desviar o olhar de si mesmo, pois o seu eu verdadeiro, que traz a marca do nada, o traço vazio, lhe é insuportável. A condição não alienada (não divertida) é o bastante para a consciência do nada materializar-se existencialmente (afetivamente) como angústia (Pondé, 2001, p.236).

O termo nada (néant) é usado por Pascal para traduzir a inconsistência do homem, sua precariedade. A incapacidade em que ele se encontra para descobrir sua origem e conseqüentemente seu fim. Nada (néant) não significa então não-ser, significa, segundo Pierre Magnard, "de nenhuma família", "de nenhuma nação". Sem o conhecimento de sua origem, é interditado ao homem encontrar os fundamentos de sua existência (Magnard, 2001, p.39-40).

Sempre utilizando o termo existencial ou existência como uma variação próxima de "vida interior consciente de si mesma", ou "percepção dessa vida interior nas suas manifestações temporais", não pretendemos fazer de Pascal um "existencialista avant la lettre", apenas procurar mostrar que na busca humana de repouso (felicidade) manifesta-se a busca inconsciente de um ser universal. A este ser a que o homem não pode chegar pelas vias naturais e, por conseguinte, encontrar segurança existencial, justificação para o seu existir.

"Sinto que posso não ter existido; pois o eu consiste no meu pensamento", afirma Pascal. "Portanto, eu, que penso, não teria existido se minha mãe tivesse morrido antes de eu ter sido animado: portanto, não sou um ser necessário. Não sou também eterno, nem infinito; mas vejo bem que há na natureza um ser necessário, eterno e infinito" (fr. 469). Enquanto Descartes saca a existência do ato de pensar: "penso, existo"; Pascal saca a sua não necessidade: "eu, que penso, não teria existido se minha mãe tivesse morrido antes de eu ter sido animado". É no interior do tempo que o filósofo situa a contingência humana. Diferentemente de Descartes que - embora o eu seja contingente, posto ser criatura $-\mathrm{o}$ situa na origem da criação. É na origem da criação que no eu pensante são impressas "sementes de verdade". Por considerar que o eu pensante traz em si mesmo essas "sementes de verdade", Descartes pode ligar o eu ao 
Absoluto, o qual lhe dá subsistência no tempo. Nada semelhante encontra-se em Pascal. Mesmo "vendo bem" que "há na natureza um ser necessário, eterno e infinito", o filósofo não pode ligar a contingência do eu à necessidade; a sua temporalidade à eternidade; a finitude do eu à infinitude de Deus, pois a consciência imediata (ver bem, sentir) é própria da ordem do coração e não da razão. Não há passagem possível, via racional, da finitude do eu a Deus. Logo o eu só pode ser pensado em sua contingência. Como ser contingente, o eu não encontra segurança existencial alguma. A consciência imediata da existência de um ser necessário, eterno e infinito não oferece ao homem nenhum socorro na busca de conhecer a si mesmo.

Como não há a possibilidade de encontrar os fundamentos do homem pela razão, pois esta só nos leva a conhecer ou a grandeza ou a miséria humana, tais como as filosofias de Epicteto e de Montaigne nos mostram; como também partir da geometria (geometria projetiva) para conhecê-lo, pois, pela geometria projetiva o observador sempre se situa fora e, nesta situação conduz a tomar o homem em sua horizontalidade, Pascal parte então das verdades reveladas as quais permitem, pela apresentação de dois estados distintos da natureza humana que elas oferecem, unir grandezas e misérias num mesmo sujeito. União esta impossível de se estabelecer pela razão, visto ser uma contradição manifesta atribuir a um mesmo sujeito grandezas e misérias.

Tendo em mente a distinção entre uma natureza sadia (antes da queda) e uma natureza enferma (depois da queda), Pascal pode sustentar que a perda de segurança existencial deve-se à queda adâmica. Queda esta que ocasionou a ruptura entre o homem e o ser por excelência. No estado anterior à queda o que constituía o eu humano era a sua relação com Deus. Relação amorosa, em que o amor-de-si era considerado em relação ao amor de Deus, ou seja, o homem amava a si mesmo porque amava Deus. Assim a alma traz nela mesma a capacidade de amar infinitamente, posto ser o objeto próprio de seu amor um ser infinito. Rompida a relação com Deus, perdido o objeto verdadeiro do amor, o homem, para preencher o vazio em sua capacidade infinita de amar, passou a amar a si mesmo com um amor desmedido, fazendo de si um Deus para si. Enquanto no estado anterior à queda havia uma proporção entre a capacidade de amar e o objeto amado, no estado presente há uma desproporção: o homem ama quase infinitamente um ser finito.

A este amor desmedido, porque não mais subordinado ao amor a Deus, Pascal chama de amor-próprio. "A natureza do amor-próprio e desse eu humano", assevera Pascal, "é não amar senão a si e não conside- 
rar senão a si. A que pode levar?", pergunta ele no fragmento 100. Para punir o orgulho do homem que o levou a querer igualar-se a Deus, Deus permitiu que ele se convertesse em Deus de seu amor-próprio, sendo por ele atormentado em todas as ações de sua vida. Para Pascal, o inferno não é o outro, o inferno somos nós mesmos, pois jamais podemos estar quietos conosco mesmo, uma vez que o nosso ser verdadeiro traz a marca do nada, o traço vazio. Perdido o objeto verdadeiro, o homem não encontra nada em si mesmo que possa satisfazê-lo. Todavia ele conserva ainda o desejo de conhecer e de ser feliz. Herança de uma primeira natureza, cuja passagem à segunda não foi completa. Esta incompletude é verificável na própria busca incessante do homem atual. Querer tudo possuir e tudo dominar para preencher o seu vazio, o seu nada, é miséria, posto não ser possível encontrar a satisfação nos objetos que, assim como o homem, são passageiros. Porém, é nesta miséria que encontramos a sua grandeza: no fundo o que o homem busca é um ser universal capaz de satisfazer a sua capacidade infinita de amar. Sem ter consciência disso, pois esta busca essencial não são "sementes de verdade" depositadas nele, mas apenas vestígios da grandeza de sua primeira natureza presente em sua segunda natureza, a busca humana da verdade e da felicidade se transforma em uma busca incessante. O repouso momentâneo que o homem encontra naquilo que, em seu estado presente, se apresenta a ele como verdade e felicidade, transformase em aguilhão, pois o coloca diante de sua miséria. Ou em outros termos, procurar resolver um problema metafísico, conquistar uma praça inimiga, concentrar-se no jogo de cartas para fazer a melhor jogada, armar estratégias na caça para capturar a presa, isto tudo implica em desviar de considerar a si, em ocupar-se de coisas para não pensar em si mesmo. Isto é que é divertimento.

Todavia, na resolução do problema metafísico, na conquista da praça inimiga, no ganho do jogo, na captura da caça, o homem encontra ilusoriamente repouso. Porém, no momento de fruir desse repouso, portanto, na volta para si, o homem depara consigo mesmo, depara com o seu nada, o seu vazio. O homem procura o repouso sem poder gozar do repouso. Pois é no repouso que, deparando com o seu nada, surge nele a angústia. Assim aquilo que o homem julga ser sua felicidade, transforma-se em aguilhão que o excita a se lançar fora de si para não ver seu eu verdadeiro. $\mathrm{O}$ divertimento torna-se então necessário para um ser que carrega a marca do nada, o traço vazio. Estar ocupado o tempo todo é o único modo que o homem encontra para não pensar em si mesmo, para livrar-se da angústia. 
A angústia e o desespero - que traduzem o termo ennui - são evidentemente ligados, pois o sentimento do vazio que surge de seu próprio nada, ligado à solidão, à inevitabilidade da morte próxima - esta que é o "arremate eterno"- e à impossibilidade de lhe atribuir alguma significação, faz surgir o desespero que, segundo Pascal, ninguém pode deixar de experimentar mesmo quando a causa não lhe apareça claramente.

Fugir do espetáculo do seu nada passa a ser necessário para que o homem subtraia-se ao desespero. O temor não aparece somente quando o homem contempla o silêncio eterno dos espaços infinitos, diante dos quais sente-se como um ponto no infinito, isto é, sente sua nulidade diante da amplidão da natureza. Ou quando o homem sente-se extraviado "nesse recanto afastado do universo". Universo este que, com a introdução do infinito, via matemática, não apresenta mais espaços qualificados nem direções privilegiadas. No universo infinito, qualquer lugar em que nos situemos equivale a qualquer outro. Não há razão de preferir estar aqui ou ali. Sem poder conferir um lugar no universo que lhe seja próprio, o homem é um ser errante na natureza. Nesta, o homem sente medo como se estivesse em uma "ilha deserta", à deriva no eterno desespero sem poder conhecer seu princípio e o seu fim. O temor aparece também quando ele está diante do espetáculo do seu nada, o qual, assim como os espaços infinitos, é silencioso. Silencioso, pois o homem não pode conferir-lhe significação alguma.

As ocupações que o homem busca para livrar-se do espetáculo do seu ser não são diversões isentas de paixões:

o homem passa a vida sem tédio jogando todos os dias coisa de pouca monta. Dai-lhe todas as manhãs o dinheiro que ele pode ganhar a cada dia, sob a condição de ele não jogar, ireis torná-lo infeliz. Dir-se-á talvez que o que ele busca é a brincadeira do jogo e não o ganho. Fazei então com que não jogue a dinheiro: ele não se animará e se aborrecerá. Não é então só a diversão que ele busca. Uma diversão desanimada e sem paixão o entediará. Ele precisa se animar e criar um engodo para si mesmo imaginando que seria feliz ganhando aquilo que não quereria que lhe fosse dado sob a condição de não jogar, a fim de que forme para si um motivo de paixão e que excite com isso o seu desejo, a sua cólera, o temor por esse objeto que formou para si como as crianças se apavoram vendo a cara que lambuzaram de tinta (Pascal, 1988, fr. 139).

É preciso então que o homem se atenha ao divertimento por paixão.

Embora Pascal não ofereça nenhuma definição de paixão, podemos dizer que ela aparece como um sentimento intenso, fixado sobre um 
objeto cuja posse é incerta. Ela é então produzida pela contrariedade (Lazzeri, 1993, p.30). Não é a presa, não é o dinheiro do jogo que o homem busca, pois se oferecemos a ele a lebre que poderia capturar na caça, ou o prêmio que poderia ganhar jogando, isto o faria infeliz. Portanto, não são as coisas que o homem busca. Ele busca a própria busca. É na busca que o homem aviva suas paixões. "Não buscamos nunca as coisas, mas a busca das coisas", sustenta Pascal. "Assim, nas comédias, as cenas alegres, sem temor, não valem nada, nem as extremas misérias sem esperança, nem os amores brutais, nem as severidades ásperas" (fr. 135).

Se é na incerteza de obter aquilo que o homem procura que ele se livra da visão de suas misérias; se é no prazer "em ver duas paixões contrárias se chocar" que ele aviva suas próprias paixões; isto revela que seu eu verdadeiro the é insuportável. Ele não encontra nada em si mesmo para ater o seu amor. O homem ama desmedidamente a si, mas não suporta a si mesmo. É preciso "criar um engodo para si mesmo" para desviar a consideração de si.

Considerar é se ver por inteiro. Considerando-se, o homem vê suas misérias, fraquezas e imperfeições. Ele percebe assim que o seu eu verdadeiro não é merecedor de amor. Necessário se faz esconder o eu verdadeiro de si mesmo e dos outros. Necessário se faz trocar o sentimento do seu nada pelas paixões nascidas da certeza que um certo objeto poderá satisfazê-lo e a incerteza de possuí-lo. É preciso preencher o vazio do eu. Para tanto, não bastam então somente as ocupações constantes. Necessário se faz atrair a admiração e a estima alheia.

Mas para que o homem possa atrair a admiração e a estima alheia sobre o seu eu, ele não poderá deixar transparecer o seu eu verdadeiro, posto não ser amável. Ele constrói um eu, enfeitando-o com todas as qualidades que são valorizadas pelos homens. Esse eu construído não é somente para arrancar a admiração e a estima dos outros, é um eu que o homem constrói para si mesmo para aplicar-lhe o seu amor. É este eu engrandecido pelas qualidades apreciadas por todos que ele tenta impor aos outros.

Não nos contentamos com a vida que temos em nós e em nosso ser: queremos viver na idéia dos outros uma vida imaginária e, para isso, esforçamo-nos por fingir. Trabalhamos incessantemente para embelezar e conservar nosso ser imaginário e negligenciamos o verdadeiro (...). Grande marca do vazio de nosso próprio ser, não estar satisfeito com um sem o outro, e renunciar muitas vezes um pelo outro (Pascal, 1988, fr. 147). 
A angústia que surge como consciência do nada que se materializa existencialmente, quando é interrompida a cadeia contínua do divertimento, leva o homem a trocar o ser pelo parecer, o eu verdadeiro pelo eu imaginário. Esta troca é a conseqüência da nulidade de ser do eu. $\mathrm{O}$ vazio do eu não é preenchido quando, narrando aos outros a difícil caçada, ou a grande jogada, ou a difícil resolução de um problema de álgebra, ele consegue arrancar dos outros a admiração. Esta somente não é capaz de negar o seu nada. Além da admiração é preciso conseguir a estima dos outros. Porque o seu eu verdadeiro lhe é insuportável, o homem não consegue viver contente consigo mesmo, é então necessário viver na idéia dos outros: "o mais belo lugar do mundo".

A maior baixeza do homem é a procura da glória, mas nisso mesmo está a maior marca de sua excelência; porque, por mais posses que tenha sobre a terra, por maior saúde e comodidade essencial que possua, não se sente satisfeito se não está na estima dos homens. Ele considera tão grande a razão do homem que, por maior vantagem que tenha sobre a terra, se não estiver situado vantajosamente também na razão do homem, não se sente contente. É o mais belo lugar do mundo; nada pode desviar o homem desse desejo... (ibidem, fr. 404).

Viver na idéia dos outros, querer ocupar este "mais belo lugar do mundo", é precisamente dominação. O desejo de dominação se explica em Pascal pelo desejo de fugir de seu próprio nada e, para isso, o desejo de se dar todo o ser possível (Lazzeri, 1993, p.39), em vista de dominar, ocupar este que é "o mais belo lugar do mundo".

A insuficiência do eu, pois somos algo e não tudo, conforme afirma Pascal no fragmento 72, opõe-se à satisfação que o homem espera de seu amor-próprio. Ele "não pode impedir que esse objeto que ama esteja cheio de defeitos e misérias", afirma Pascal. "Quer ser grande e acha-se pequeno; quer ser feliz e acha-se miserável; quer ser perfeito e acha-se cheio de imperfeições; quer ser o objeto do amor e da estima dos homens, e vê que seus defeitos só merecem deles aversão e desprezo" (fr. 100).

Não podendo renunciar à sua condição miserável, a única saída é negar esta condição no conhecimento de si e no conhecimento que os outros têm do eu. E para negar isso, é preciso mudar o olhar sobre si para não mais perceber suas propriedades. Ora, como há vestígios da grandeza de sua primeira natureza em seu estado atual, o desejo primeiro da vontade do ser universal e perfeito permanece. Como conseqüência desse desejo confuso, o nada e a imperfeição não podem desaparecer. 
A contradição entre o amor-próprio e o estado do objeto desse amor que priva a vontade da satisfação que ela procura, engendra, afirma Pascal, "a mais injusta e criminosa paixão que se possa imaginar: pois o homem concebe um ódio mortal contra essa verdade que o repreende e o convence de seus defeitos" (fr. 100). Para negar essa verdade do eu, é preciso destruí-la não somente no conhecimento que se tem de si, mas também naquele que os outros têm do seu eu, pois toda reprovação alheia sustenta a idéia do nada do eu.

Do mesmo modo que o eu lança-se fora de si buscando possuir os bens exteriores (riquezas, cargos públicos, por exemplo) para não ver o seu vazio, também na busca de passar do vazio a Deus, ou seja, de fazer do seu eu um Deus para si e para os outros, o eu põe-se fora de si para não mais perceber suas misérias. Ao invés de desviar-se de sua condição pela alienação nas coisas exteriores, o eu agora desvia o olhar de si, alienando-se no espírito dos outros. O meio para isso reside na aprovação de seu comportamento pelos outros, cuja conseqüência é a homenagem que os outros prestam às qualidades que o eu deixa aparecer.

A grandeza do outro não é vista pelo eu como aquela idéia obscura que todos trazem como vestígios de sua primeira grandeza: o desejo de atingir o ser universal. O eu toma tal desejo como exclusivamente seu, devido ao amor-próprio. A grandeza do outro é vista somente como a estima que ele pode dispensar ao eu. Esta estima é que torna o eu adequado a seu desejo de grandeza e de potência.

A estima é compreendida, em Pascal, como uma avaliação das qualidades e das potências acompanhadas de um sentimento de aprovação. Assim para atrair sobre si a estima dos outros o eu deve mostrar somente as qualidades que todos aprovam, pois se deixar aparecer o que é realmente poderá suscitar nos outros a aversão e o desprezo. "Temos uma idéia tão elevada da alma do homem”, assevera Pascal, “que não podemos tolerar que sejamos desprezados e não estimados por uma alma, e toda a felicidade dos homens consiste nessa estima" (fr. 400).

A estima recebida do outro como aprovação leva o eu ao contentamento. O contentamento, por sua vez, não é outra coisa senão a glória: o eu admira a si mesmo na estima do outro, isto é, no sentimento favorável que o outro tem do eu (Pascal, 1988, fr.82, 151, 158, 404). É este desejo de glória que faz que todos os homens busquem ocupar "o mais belo lugar do mundo": a alma alheia. Glória vã na verdade, pois para ocupar a idéia do outro, para atrair a estima do outro sobre o eu, forjamos um eu enfeitando-o com as qualidades que sabemos ser aprovadas por todos, e é essa imagem de um eu engrandecido que apresentamos aos outros. 
O sentimento de glória determina o amor-próprio a dirigir a imaginação para a única consideração das qualidades positivas e a não considerar aquelas que se opõem a um tal amor, ou seja, aquelas que merecem dos outros aversão e desprezo. É olhando a si mesmo através do olhar do outro sobre o eu que o eu passa a ignorar as suas fraquezas e imperfeições. No olhar do outro, na imagem que o outro tem do eu, é que o eu se aliena. E é por isso que o conhecimento de si encontra-se destruído. Destruído, pois a imagem engrandecida do eu, com as qualidades aprovadas por todos esconde o eu verdadeiro de si mesmo. $\mathrm{O}$ eu imaginário, alienado na imagem de si no outro, preenche o vácuo que há entre o eu verdadeiro - com suas fraquezas e imperfeições - e a vontade de se amar.

A imagem do eu se apresenta como um véu que impede o eu de ver o seu ser mais profundo. Mas não só. Ela impede também o eu de se amar tal como é, pois o que o eu ama é esse outro de si, que é a imagem de si estimada pelo outro. Ora se o eu não se ama tal como é, o amorpróprio é desamor.

Para que o amor-próprio seja possível, o eu deve usar de todos os artifícios para que o seu nada não ressurja. Para isso, primeiro: ele não deve deixar aparecer suas imperfeições; e, segundo: ele deve utilizar-se de todos os meios para que sejam conhecidas por todos as qualidades ou potências que possam ser aprovadas. Nós não expomos a nós mesmos, apenas expomos as qualidades que apreciamos e que julgamos ser apreciadas pelos outros. O amor-próprio, o desejo de estima, ocupa o lugar central nas relações humanas. Por isso é que se faz conhecer as qualidades de julgamento, de memória, de força, de saber, de saber fazer, nas conversas, na dança, na caça, no jogo, nas batalhas ganhas, na execução dos negócios, nas descobertas científicas, na liberdade de espírito, na sabedoria. É assim também por que os nobres se apresentam com muita pompa para mostrar a quantidade de empregados que possuem, exigindo, com isso, o respeito exterior como signo de estima.

Ser elegante não é demasiado vão, pois é mostrar que um grande número de pessoas trabalha para si; é mostrar, pelos cabelos, que se tem um criado grave, um perfumista, etc.; pelo ornato, o fio, os passamanes, etc. Ora, não é simples aparato, nem simples arnês, ter vários braços. Quanto mais braços se têm, mas forte se é. Ser elegante é mostrar a própria força (Pascal, 1988, fr. 316).

A exibição constante das qualidades que tem por finalidade a aprovação dos outros leva em Pascal o nome de vaidade. Vaidade porque, expondo suas qualidades aos outros, cada um procura substituir o nada 
do eu pela aparência, deixando no espírito do outro uma imagem dessas qualidades.

Se temos tranqüilidade, ou generosidade, ou fidelidade, apressamo-nos em fazê-lo saber, a fim de ligar essas virtudes a esse nosso outro ser; e de bom grado as destacaríamos de nós para as juntá-las a ele; seríamos prazerosamente poltrões para adquirir a reputação de ser corajosos (Pascal, 1988, fr. 147).

O nada do eu só poderá ser substituído se a estima adquirir a reputação, esta forma pública que nada mais é do que a aprovação das qualidades do eu por todos os outros. É exatamente esse reconhecimento público que o eu procura adquirir ao mostrar a todos suas qualidades.

Para que a estima adquira a reputação e, com isso, o eu atinja a satisfação nessa imagem que ele faz de si, é preciso zelar para que o eu imaginário, o eu engrandecido não desapareça no espírito do outro. Por isso o eu fantasia uma vida imaginária para viver não em si mesmo, mas nesse outro que é a imagem de si no outro.

O eu imaginário é fruto do próprio nada do eu, pois é devido à nulidade de ser do eu que o homem troca o eu verdadeiro (cheio de fraquezas e imperfeições) pelo eu imaginário (o eu que se toma por Deus). Esse ídolo que o eu fabrica para si e para os outros, o impede de ver suas misérias e também que os outros a vejam. "O homem não passa, portanto, de disfarce, mentira e hipocrisia, tanto em face de si próprio como em relação aos outros. Não quer que lhe digam verdades e evita dizê-las aos outros; e todos esses propósitos, tão alheios à justiça e à razão, têm em seu coração raízes naturais" (fr. 100).

Desejando ser o centro da admiração alheia, o eu forja uma imagem de si e tenta impô-la aos outros. Esta imagem, conforme vimos, o eu a toma por realidade. É uma imagem forjada para si mesmo e para os outros. Como imagem forjada é uma ilusão que, devido à credibilidade, iguala-se à realidade. Logo o eu é enganador.

Interpondo eus imaginários entre ele (que se quer como Deus) e ele mesmo (cheio de imperfeições), o eu se livra de pensar a verdade que o convence de seus defeitos; e interpondo eus imaginários entre ele (cheio de misérias) e os outros, o eu impede os outros de ver suas fraquezas. Forjar um ídolo para si é o único modo que o eu encontra para aplicar o seu amor. Todavia uma vez que, para satisfazer-se nesse outro de si, essa imagem de si necessita da aprovação alheia, isso implica que o eu tomado por Deus não basta a si mesmo. Longe então de dar todo o ser possível, o ídolo que o eu forja para si e para os outros, o leva a trabalhar 
incessantemente para conservá-lo na idéia dos outros. Logo o eu é escravo de sua própria imagem. Escravidão infeliz (Lazzeri, 1993, p.35), uma vez que o eu necessita do olhar de aprovação do outro para satisfazer-se consigo mesmo. Sempre ocupado em conservar esse outro de si na idéia do outro, o eu nega conhecer e amar-se tal como é. É negando a si que o sujeito do amor-próprio perde-se a si mesmo, pois impede a si e também aos outros de conhecer que o seu desejo mais profundo é o desejo infinito de atingir o ser universal. Tanto é assim que, na ausência do ser universal, o eu toma-se por Deus. Narciso não nos abandona, posto o eu perder-se na imagem que ele faz de si.

Não conseguindo preencher o desejo infinito de atingir o ser universal com o seu eu verdadeiro, isto é, com suas forças, o eu só poderá se amar infinitamente se for estimado universalmente. Somente com uma estima universal ele pode adequar a dimensão do objeto a seu desejo. Com efeito, ele deverá renovar constantemente as operações pelas quais ele adquire a reputação e a glória. Mas por mais que ele intensifique essas operações, jamais poderá atingir a plena realização do seu desejo: ser tudo para todos.

Quanto mais o eu se toma por Deus, mas distante de si ele permanece. Quanto mais o eu quer ser perfeito, mais imperfeito se torna. Quanto mais ser quer conferir a si, mais longe do ser universal ele se encontra.

Quem não odeia em si o seu amor-próprio, e esse instinto que o leva a fazer-se Deus, é bem cego. Quem não vê que nada é tão oposto à justiça e à verdade? Porque é falso que mereçamos isso; e é injusto e impossível chegar a isso, uma vez que todos pedem a mesma coisa. É, pois, em uma manifesta injustiça que nascemos, da qual não podemos desfazer-nos e da qual devemos desfazer-nos (Pascal, 1988, fr. 492).

Enquanto no fragmento 100, o eu enganador é alheio à justiça e à verdade, pois o propósito de enganar a si e aos outros tem em seu coração "raízes naturais", neste fragmento 492, o eu que faz de si um Deus para si e para os outros, é também apresentado como "oposto à justiça e à verdade", manifestando a injustiça na qual nascemos. Mas por que o eu enganador, o eu que se faz Deus, é injusto para si e para os outros? Em primeiro lugar porque o sujeito do amor-próprio não ama a si mesmo. $\mathrm{O}$ que ele ama é uma imagem de si em relação à qual comporta-se servilmente. Em segundo lugar porque nutre uma aversão à verdade presente em seu próprio ser. Embaraçoso é o sujeito do amor-próprio, pois ninguém em sã consciência sustenta preferir a mentira em detrimento da 
verdade, entretanto faz tudo para evitar a verdade que o convence de seus defeitos e não suporta que os outros digam verdades a ele. E, uma vez que o sujeito do amor-próprio faz de si um Deus para si e para os outros, escondendo o seu eu verdadeiro, a imagem de si é a única maneira que o eu encontra para vazar seus olhos agradavelmente e para vazar os dos outros. Logo a imagem de si que o eu deixa aparecer cega a si e aos outros. A aparência nos cega. Aquilo que nos é dado ver, isto é, a visibilidade que o eu deixa transparecer, transforma-se em seu oposto.

O sujeito do amor-próprio é também injusto com os outros, pois ao desejar ser tudo para todos, nega aos outros o desejo de se tomar por Deus. Deus é uma singularidade. Ao tomar-se por Deus, o eu nega sua particularidade e procura afirmar-se como uma singularidade, negando assim esse mesmo desejo aos outros. Além disso, por querer ser amado pelos outros como se fosse um Deus, o sujeito do amor-próprio rompe a reciprocidade do amor. A justiça do amor é precisamente a igualdade. Só pode haver reciprocidade na relação amorosa se houver igualdade. Assim, impondo-se aos outros como se fosse um Deus, desejando ser amado e admirado por todos, o eu rompe aquilo mesmo que constitui a relação amorosa: a igualdade. Logo, o sujeito do amor-próprio é tirano. Por ser tirano, o sujeito do amor-próprio se faz odiar, por isso mesmo é que o homem deve odiar o seu amor-próprio. "O eu tem duas qualidades", afirma Pascal. "É injusto em si, fazendo-se centro de tudo; é incômodo aos outros, querendo sujeitá-los: pois cada eu é o inimigo e desejaria ser o tirano de todos os outros" (fr. 455).

Pascal define a tirania como "o desejo de dominação, universal e fora de sua ordem" (fr. 332). Ele apresenta as experiências humanas divididas em três ordens: ordem do corpo, ordem do espírito e ordem do coração (ou caridade). O domínio dos bens exteriores é próprio da ordem do corpo; o conhecimento, próprio da ordem do espírito. Esses domínios, o eu os agrega à imagem de si exigindo com isso a estima de todos, revelando assim uma outra face de sua injustiça: como a estima (amor) é da ordem do coração, o eu quer receber, situado em uma ordem, o que é próprio de uma outra ordem. Situado na ordem do corpo ou do espírito, ele quer receber o que é próprio da ordem do coração. Logo o sujeito do amor-próprio apresenta-se na desordem.

Toda a tentativa humana de preencher o seu nada, o seu traço vazio, procurando passar desse vazio ao Deus que deseja substituir, está, como vimos, fadada ao fracasso. Nada poderá preencher o seu vazio. A busca 
de subsistir na idéia do outro, no reconhecimento alheio é uma busca desesperada de conferir ser a um ser no qual a marca é a ausência de ser.

"A marca do nada", "o traço vazio" que o homem traz no mais profundo do seu ser, interdita-lhe encontrar um ponto fixo em si mesmo, o qual lhe possibilitaria encontrar alguma segurança. A angústia e a necessidade de divertir-se, esse vai e vem constante do interior ao exterior, mostra que o homem é um ser cindido, não há em si mesmo um ponto de ancoragem. Ilusório, portanto, é procurar compreender a si através da coincidência imediata de um representante e de um representado, na clareza e distinção da idéia de um eu abstrato, como pretende Descartes. Ilusório também é procurar dominar o tempo ao se expressar no tempo, como faz Montaigne que, ensaiando-se, erige um monumento para si. "Sou eu mesmo a matéria desse livro", "é a mim mesmo que pinto", escreve ele ao leitor dos Ensaios. A tentativa de Montaigne de dominar o tempo, o monumento que erige para si a fim de subsistir na idéia dos outros, mesmo quando ele não mais existir, traduz a incapacidade do homem de aceitar a aniquilação total.

Talvez a saída possível, capaz de dar algum sentido a essa vida efêmera, seja aquela que Pascal aponta no fragmento 233, intitulado "Infinito. Nada", mais conhecido como argumento da Aposta. Apostando na existência divina, o homem vislumbra a possibilidade, de jogando o finito, ganhar o infinito, jogando a vida cujo fim é a morte, ganhar a vida eternamente feliz. Toda aposta é arriscada, corre-se o risco de ganhar ou de perder. Por ser arriscada, há a esperança do ganho e o temor da perda. "Não há esperança sem temor, nem temor sem esperança", dirá Espinosa. Assim mesmo aquele que aposta na existência divina, encontra-se na inquietude, sem saber quando o jogo será interrompido, isto é, quando a vida será interrompida e ela é sempre interrompida quando menos se espera. Jamais ele poderá estar certo de que será resgatado do nada eterno que é a morte.

Finalmente a morte, que nos ameaça a cada instante, deve infalivelmente nos levar em poucos anos à horrível necessidade de sermos eternamente aniquilados ou eternamente infelizes.

Mas não há nada de mais real do que isso, nem nada mais terrível. Aparentemos a coragem que quisermos: eis o fim que espera a mais bela vida do mundo... (Pascal, 1988, fr. 194). 
PARRAZ, I. Pascal's existentialism. Trans/Form/Ação (São Paulo), v.26, p.115128, 2003.

n ABSTRACT: Inscribed in his innermost being, man carries "the mark of nothing", "the empty trace". Since he carries that emptiness, he does everything to fill it up. He creates "imaginary selves" with the qualities which he values and which other people also value, and tries to impose them on others, seeking their admiration. The imaginary self allows him to get rid of the vision of his true self. That self which puts him in front of his emptiness produces in him tedium and uneasiness.

n KEYWORDS: Nothingness; anguish; fun; admiration; esteem.

\section{Referências bibliográficas}

CARRAUD, V. Pascal et la philosophie, Paris: PUF, 1992.

LAZZERI, C. Force et justice dans la politique de Pascal, Paris: PUF, 1993.

MAGNARD, P. Le vocabulaire de Pascal, Paris: Ellipses, 2001.

PASCAL, B. Pensamentos. São Paulo: Nova Cultural, 1988. (Os Pensadores).

PONDÉ, L. F. O homem insuficiente. Comentários de antropologia pascaliana. São Paulo: EDUSP, 2001. 